\title{
GLASS TRANSITION AND DEGREE OF CONVERSION OF A LIGHT-CURED ORTHODONTIC COMPOSITE
}

\author{
Michela M. D. S. SOSTENA ${ }^{1}$, Renata A. NOGUEIRA², Carlos R. GRANDINI ${ }^{3}$, João Carlos Silos MORAES ${ }^{4}$
}

1- DDS, MSc Graduate student, Department of Physics and Chemistry, São Paulo State University, Ilha Solteira, SP, Brazil.

2- DDS, MSc Graduate student, Department of Physics, São Paulo State University, Bauru, SP, Brazil.

3- DDS, MSc, PhD Adjunct Associate Professor, Department of Physics, São Paulo State University, Bauru, SP, Brazil.

4- DDS, MSc, PhD Full Professor, Department of Physics and Chemistry, São Paulo State University, Ilha Solteira, SP, Brazil.

Corresponding address: Prof. João Carlos Silos Moraes - Departamento de Física e Química - UNESP - Campus de Ilha Solteira - Av. Brasil, 56 15.385 -000 - Ilha Solteira - São Paulo - Brasil - Phone: +55-18-37431029 - Fax: +55-18-3742-4868 - e-mail: joca@dfq.feis.unesp.br.

Received: August 25, 2008 - Modification: September 23, 2008 - Accepted: July 21, 2009

\begin{abstract}
$O$

bjective: This study evaluated the glass transition temperature $\left(\mathrm{T}_{\mathrm{g}}\right.$ ) and degree of conversion (DC) of a light-cured (Fill Magic) versus a chemically cured (Concise) orthodontic composite. Material and Methods: Anelastic relaxation spectroscopy was used for the first time to determine the $\mathrm{T}_{\mathrm{g}}$ of a dental composite, while the $\mathrm{DC}$ was evaluated by infrared spectroscopy. The light-cured composite specimens were irradiated with a commercial LED light-curing unit using different exposure times (40, 90 and $120 \mathrm{~s}$ ). Results: Fill Magic presented lower $\mathrm{T}$ than Concise $\left(35-84^{\circ} \mathrm{C}\right.$ versus $\left.135^{\circ} \mathrm{C}\right)$, but reached a higher DC. Conclusions: The results of this study suggest that Fill Magic has lower $\mathrm{T}_{\mathrm{g}}$ than Concise due to its higher organic phase content, and that when this light-cured composite is used to bond orthodontic brackets, a minimum energy density of $7.8 \mathrm{~J} / \mathrm{cm}^{2}$ is necessary to reach adequate conversion level and obtain satisfactory adhesion.
\end{abstract}

Key words: Orthodontic composite. Glass transition temperature. Degree of conversion. Mechanical spectroscopy. Infra-red spectroscopy.

\section{INTRODUCTION}

Orthodontic cements, composites, and hybrid resin cements are used to bond orthodontic components to teeth ${ }^{4}$. Two types of orthodontic composites are available in the market: light cured and chemically cured materials. Lightcured composites are preferred by orthodontists due to their longer working time for optimal bracket placement, before the curing process is initiated by exposure to visible light. The disadvantage of these composites is that, in general, orthodontic brackets are made of materials with low visible transmission coefficient, and the composite layer is irradiated through the contour of the bracket edges ${ }^{1,6}$.

The importance of the curing efficiency with regards to the performance of composites is well established. The physical and mechanical properties of these materials are influenced by the level of monomer to polymer conversion achieved during the polymerization process 9 . Light intensity and irradiation time are important factors to achieve an appropriate degree of conversion (DC) $)^{15}$ of photoactivated composites,. Mechanical properties, such as tensile and compressive strengths, depend on the degree of the resin matrix cure ${ }^{5}$. On the other hand, the bond strength of orthodontic composites must be sufficient to withstand the masticatory forces, the stresses exerted by orthodontic mechanics, and variations in the oral environment.

An important physical property of the cured matrix is indicated by the glass transition temperature $\left(\mathrm{T}_{\mathrm{g}}\right)$. Inadequate polymerization determines a low final $\mathrm{T}_{\mathrm{g}}$ of a material. The $\mathrm{T}_{\mathrm{g}}$ of an orthodontic composite is only of relevance if it lies within the range of intraoral temperatures ${ }^{7,11}$. Intraoral temperatures that exceed the $T_{g}$ may result in material softening and consequently in bracket debonding ${ }^{14}$.

The purpose of this study was to evaluate the $\mathrm{T}_{\mathrm{g}}$ and DC of a light-cured versus a chemically cured orthodontic composite using different exposure times.

\section{MATERIAL AND METHODS}

The specifications, main ingredients and manufacturers of the orthodontic composites used in this study (Fill Magic and Concise) are displayed on Table 1.

Beam-shaped specimens of each material were prepared in a brass mold with internal dimensions of $40 \times 4 \times 4 \mathrm{~mm}$ for $\mathrm{Tg}$ measurements. The samples were kept at room temperature and subjected to the measurements only after completely cured. Equal volumes of Concise's Paste A 
TABLE1- Orthodontic adhesives used in the study

\begin{tabular}{|c|c|c|c|c|}
\hline Material & Manufacturer & Polymerization mode & Monomers & Inorganic content (wt\%) \\
\hline Fill Magic & $\begin{array}{l}\text { Vigodent SA, Rio } \\
\text { de Janeiro, RJ, Brazil }\end{array}$ & One paste, light-cured & $\begin{array}{l}\text { BisGMA, Methacrylate } \\
\text { acid ester }\end{array}$ & $38.1^{*}$ \\
\hline Concise & $\begin{array}{l}\text { 3M ESPE, St. Paul. } \\
\text { MN, YSA }\end{array}$ & $\begin{array}{l}\text { Two pastes, } \\
\text { chemically-cured }\end{array}$ & BisGMA, TEGDMA & $77.4^{\star}$ \\
\hline
\end{tabular}

bisGMA = bisphenol $\mathrm{A}$ glycol dimetacrylate; TEGDMA = triethyleneglicol dimethacrylate. $\left({ }^{*}\right)$ Values obtained in the present study.

TABLE 2- Glass transition temperature $\left(\mathrm{T}_{\mathrm{g}}\right)$ and degree of conversion (DC) of the orthodontic composites evaluated in the study

\begin{tabular}{lcc}
\hline Material & $\mathbf{T}_{\mathbf{g}}\left({ }^{\circ} \mathbf{C}\right)$ & DC (\%) \\
\hline Concise & 135 & $57.7 \mathrm{a}$ \\
Fill Magic & & \\
$40 \mathrm{~s}$ & 35 & $56.3 \mathrm{a}$ \\
$90 \mathrm{~s}$ & 50 & $56.5 \mathrm{a}$ \\
$120 \mathrm{~s}$ & 84 & $64.1 \mathrm{~b}$ \\
\hline
\end{tabular}

DC means follows by same small letter indicate no statistical difference by the Tukey's test at $5 \%$ of probability.

(containing the accelerator) and Paste B (containing the catalyst) were mixed according to the manufacturer's instructions. Samples of Fill Magic composite were irradiated on the opposite faces of the lateral surface for 40 , 90, and 120 s. A LED light curing unit (Gnatus - LDIII model) with a power density of $65 \mathrm{~mW} / \mathrm{cm}^{2}$ was used as visible light source. The power output was measured with a power meter (Model 13PEM001; Melles Griot, Irvine, CA, USA).

Measurements of anelastic relaxation (internal friction) were performed in a torsion pendulum, operating at 1.4 and $9.4 \mathrm{~Hz}$ frequency range. Internal friction as a function of temperature was carried out between 100 and $380 \mathrm{~K}$, with a heating rate of $1 \mathrm{~K} / \mathrm{min}$ and pressure of approximately $10^{-6}$ mbar. The sample is placed to vibrate at a fixed frequency, and the sample temperature is changed so that mechanical relaxation can be observed. The technique enables measuring the elastic modulus (related to the oscillating frequency) and the internal friction (the elastic energy loss, $Q^{-1}$ ) as a function of the temperature. The internal friction is determined by the free decay method ${ }^{12}$ :

$$
Q^{-1}=\tan \delta=\frac{1}{\pi N} \ln \frac{A_{o}}{A_{N}}
$$

where $N$ is the number of oscillating cycles, during which the amplitude decreases from $A_{0}$ to $A_{N}$. The peak observed on the curve tand versus temperature reflects the glass transition temperature.

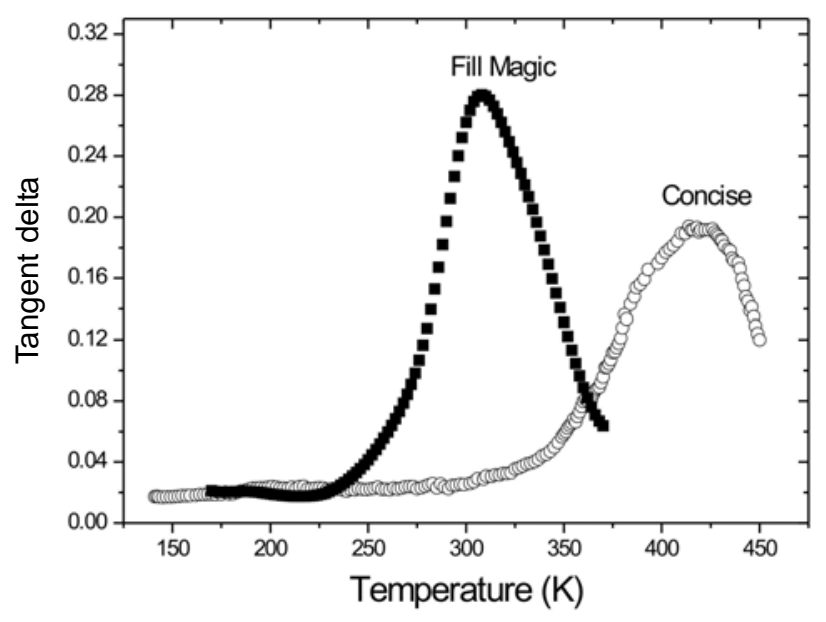

FIGURE 1- Tangent delta for Concise and Fill Magic composites

For the Fourier transform infra-red (FTIR) analysis, a small amount of each material was placed between two microscope slides that were compressed to produce $0.4-\mathrm{mm}$ thick films. For Concise, films of uncured pastes A and B as well as films of the cured mixture were prepared. For Fill Magic, five films of $0.4 \mathrm{~mm}$ of uncured were prepared for each exposure time. These five films were superposed one on the other to form a sample of $2 \mathrm{~mm}$ of thickness. In this way, it is believed that the reached conversion level is similar that obtained in the sample used for TG measurements. After each sample was irradiated, the first and the last films were used for DC measurements. Five samples for each exposure time were prepared.

The DC was evaluated using two absorption bands. One at $4740 \mathrm{~cm}^{-1}$ associated to a combination of $=\mathrm{CH}_{2}$ aliphatic bands and an aromatic band at $4623 \mathrm{~cm}^{-1}$. This latter band is used as an internal standard of normalization. The DC was determined base on the decrease of $4740 \mathrm{~cm}^{-1}$ absorption on the FTIR spectra as follows:

$$
D C \%=\left[1-\frac{\left(A_{1} / A_{0}\right)_{\text {cured }}}{\left(A_{1} / A_{0}\right)_{\text {uncured }}}\right] \times 100
$$

where $A_{1}$ and $A_{0}$ are the height of aliphatic and aromatic absorption, respectively. Spectra of uncured and cured films were recorded by transmission method in a FTIR spectrometer (Nexus 670; Nicolet Ramsey, MN, USA), using 64 scans at a resolution of $4 \mathrm{~cm}^{-1}$. 


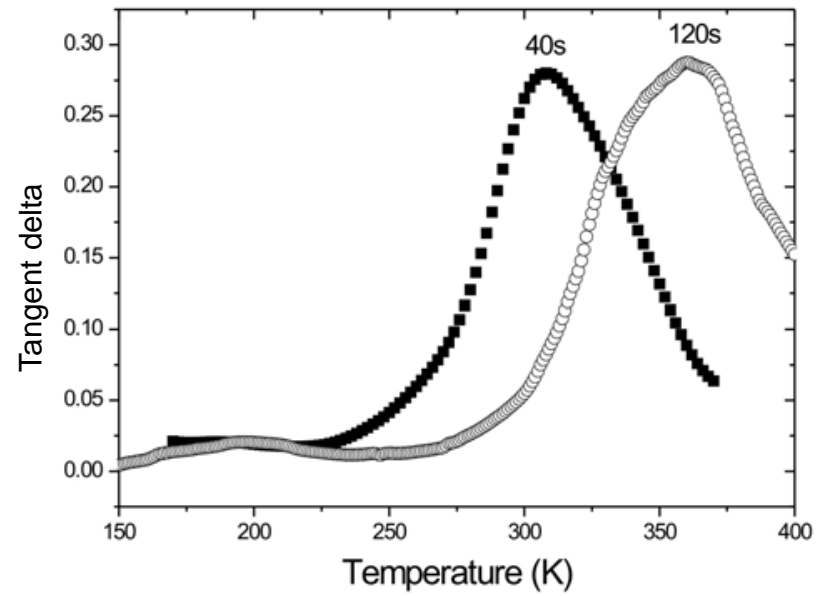

FIGURE 2- Tangent delta for Fill Magic composite for 40and 120-s exposure times

The statistical analysis of the DC results was performed by one-way ANOVA and Tukey multiple comparison test at $\mathrm{p}=0.05$ significance level.

\section{RESULTS AND DISCUSSION}

$\mathrm{T}_{\mathrm{g}}$ and $\mathrm{DC}$ values obtained for the two composites are presented in Table 2. The DC of each sample is the average between the DC value at the surface (first film) and at the depth of $2 \mathrm{~mm}$ (last film). The DC of Concise was similar to that obtained by Eliades, et al. ${ }^{2}(2000)(52.0 \pm 6.0)$. On the other hand, the Fill Magic presents a DC statistically higher than Concise only for the exposure time of 120s. For the Fill Magic, the Tg value changed with the exposure time, providing an increase of almost $50{ }^{\circ} \mathrm{C}$ when the exposure time was increased from 40 to $120 \mathrm{~s}$, while the DC increased $13.9 \%$. Thus, the two studied properties were influenced by irradiation time suggesting the necessity of a least energy quantity for the material to reach an appropriate level of polymerization and consequently a bigger value of Tg. From the results it can be observed that the best DC and Tg values were obtained with an energy density (= power density $\mathrm{x}$ exposure time) of $7.8 \mathrm{~J} / \mathrm{cm}^{2}$.

The differences observed in the $\mathrm{T}_{\mathrm{g}}$ and $\mathrm{DC}$ of the studied composites can be attributed to the structural characteristics of each material. Factors such as monomer type and inorganic filler type and content, determine the physical and mechanical properties of cured composite. Concise contains the BisGMA and TEGDMA monomers in its organic matrix and $77.4 \mathrm{wt} \%$ of quartz as inorganic filler. Fill magic contains BisGMA and methacrylic acid ester as monomers and 38.1 $\mathrm{wt} \%$ of fluorsilicate glass as inorganic filler.

$\mathrm{T}_{\mathrm{g}}$ determines the physical state of a polymer and influences several properties. Tg variation has been attributed to various molecular parameters, such as molecular weight, stiffness of the crosslinked chains and free volume entrapped in the network. ${ }^{10}$ Other investigations have shown that $T_{g}$ can be affected by crosslinked chains and filler content $^{3,8,13,16}$. Figure 1 shows the loss tangent curve of Fill
Magic and Concise composites. The analysis of curve behavior shows that Concise has a lower and broader loss tangent peak and a higher Tg than Fill Magic. An increase of filler content causes a broadening ${ }^{16}$ and a decreasing ${ }^{13}$ in the loss tangent peak. Therefore, the higher filler content of Concise explains the observed difference in the loss tangent curve when compared to Fill Magic. On the other hand, the different organic/inorganic phase concentration ratios between the composites explain the difference in the $\mathrm{Tg}$ observed for the materials. The larger inorganic phase concentration of Concise $(77.4 \mathrm{wt} \%)$ promotes a decreased of polymeric chain mobility and consequently increases its Tg.

Figure 2 shows the loss tangent versus exposure time curve obtained with Fill Magic. A larger exposure time increased the DC (Table 2) and the crosslinked chain concentration, thus promoting an increase of $\mathrm{T}_{\mathrm{g}}$. It is important to observe that the Tg values obtained with 40 and $90 \mathrm{~s}$ are within the range of oral environment temperature. The fact that Fill Magic presented a higher DC and smaller $\mathrm{T}_{\mathrm{g}}$ than Concise suggests that, despite the greater level of conversion, its final structure might have a larger mobility and, consequently, a smaller cross-link chains density.

\section{CONCLUSIONS}

Within the limitations of this study, the following conclusions may be drawn: 1. Fill Magic presents a lower Tg than Concise due to its higher organic phase content; 2. When Fill Magic is used to bond orthodontic brackets, a minimum energy density of $7.8 \mathrm{~J} / \mathrm{cm}^{2}$ is necessary to reach adequate conversion level and obtain satisfactory adhesion.

Only with the results obtained in this work, it is impossible to predict which of the two composites will promote better bracket to tooth adhesion. Further studies, as for instance bonding strength, are necessary to be performed.

\section{ACKNOWLEDGMENTS}

We acknowledge Vigodent SA for supplying the Fill Magic orthodontic composite and FAPESP, CNPq, and CAPES for their financial support. One of the authors is grateful to Prof. Jean Richard Dasnoy Marinho for valuable discussions.

\section{REFERENCES}

1- Eliades T, Eliades G, Brantley WA, Johnston WM. Polymerization efficiency of chemically cured and visible light-cured orthodontic adhesives. Am J Orthod Dentofacial Orthop. 1995;108:294-301.

2- Eliades T, Eliades G, Bradley TG, Watts DC. Degree of cure of orthodontic adhesives with various polymerization initiation modes. Europ J Orthod. 2000;22:395-9. 
3- Emami N, Söderholm KJM. Dymamic mechanical thermal analysis of two light-cured dental composites. Dent Mater. 2005;21:977-83.

4- Ewoldsen N, Demke RS. A review of orthodontic cements and adhesives. Am J Orthod Dentofacial Orthop. 2001;120:45-8.

5- Ferracane JL, Greener EH. The effect of resin formulation on the degree of conversion and mechanical-properties of dental restorative resins. J Biomed Mater Res. 1986;20:121-31.

6- Joseph VP, Rossouw E. The shear bond strengths of stainless-steel and ceramic brackets used with chemically and light-activated composite resins. Am J Orthod Dentofacial Orthop. 1990;97:121-5.

7- Knox J, Jones ML, Hubsch P, Middleton J. The influence of orthodontic adhesive properties on the quality of orthodontic attachment. Angle Orthod. 2000;70:241-6.

8- Lu H, Lovell LG, Bowman CN. Exploiting the heterogeneity of crosslinked photopolymers to create high-Tg polymers from polymerizations performed at ambient conditions. Macromolecules. 2001;34:8021-5.

9- Maffezzoli A, Della Pietra A, Rengo S, Nicolais L, Valletta G. Photopolymerization of dental composite matrices. Biomaterials. 1994;15:1221-8.

10- Min BG, Stachurski ZH, Hodgkin JH. Cure kinetics of elementary reactions of a DGEBA/DDS epoxy resin: 1. Glass transition temperature versus conversion. Polymer. 1993;34:4908-12.

11- Moore RJ, Watts JTF, Hood JAA, Burritt DJ. Intra-oral temperature variation over 24 horus. Eur J Orthod. 1999;21:249-61.

12- Nowick AS, Berry BS. Anelastic relaxation in crystalline solids. New York: Academic; 1972.

13- Papadogiannis Y, Boyer DB, Helvatjouglu-Antoniades M, Lakes RS, Kapetanios C. Dynamic viscoelastic behavior of resin cements measured by torsional resonance. Dent Mater. 2003;19:510-6.

14- Rueggberg FA, Maher FT, Kelly MT. Thermal-properties of a methyl methacrylate-based orthodontic bonding adhesive. Am J Orthod Dentofac Orthop. 1992;101:342-9.

15- Rueggeberg FA, Caughman WF, Curtis JW Jr. Effect of light-intensity and exposure duration on cure of resin composite. Oper Dent. 1994;19:2632 .

16- Lawrence EN, Landel RF. Mechanical properties of polymers and composites. 2nd ed. New York: Marcel Dakker INC; 1994. p. 422-9. 